\title{
Comparison of Refraction and Ocular Biometry in European Caucasian Children Living in Northern Ireland and Sydney, Australia
}

\author{
Amanda N. French, ${ }^{1}$ Lisa O'Donoghue, ${ }^{2}$ Ian G. Morgan, ${ }^{3}$ Katbryn J. Saunders, ${ }^{2}$ Paul Mitchell, ${ }^{4}$ \\ and Kathryn A. Rose ${ }^{1}$
}

Purpose. To compare refraction and ocular biometry in European Caucasian children aged 6 to 7 years and 12 to 13 years, living in Sydney, Australia, and Northern Ireland.

Methods. All children had a comprehensive eye examination, including cycloplegic (cyclopentolate 1\%) autorefraction and ocular biometry. Hyperopia was defined as a right spherical equivalent refraction (SER) of $\geq+2.00$ diopters (D), myopia as $\leq-0.50 \mathrm{D}$, and astigmatism as a cylindrical error of $\geq 1.00 \mathrm{D}$.

Results. The mean SER was similar at age 6 to 7 years $(P=0.9)$; however, at 12 to 13 years, children in Northern Ireland had a significantly less hyperopic mean SER $(+0.66 \mathrm{D})$ than children in Sydney $(+0.83 \mathrm{D}, P=0.008)$. The prevalence of myopia, hyperopia, and astigmatism was significantly greater in Northern Ireland than Sydney at both ages (all $P<0.03$ ). The distribution of refraction was highly leptokurtic in both samples, but less so in Northern Ireland (kurtosis: 6-7 years of age, $7.2 ; 12-13$ years of age, 5.9) than Sydney (kurtosis: 6-7 years of age, 15.0; 12-13 years of age, 19.5).

Conclusions. European Caucasian children in Northern Ireland have a greater prevalence of myopia, hyperopia, and astigmatism when compared to children living in Sydney. Risk factors for myopia such as parental myopia, parental education, and educational standards do not appear to explain the differences. Further work on levels of near work and time spent outdoors is required. (Invest Ophthalmol Vis Sci. 2012;53:4021-4031) DOI:10.1167/iovs.12-9556

From the ${ }^{1}$ Discipline of Orthoptics, Faculty of Health Sciences, University of Sydney, Sydney, NSW, Australia; the ${ }^{2}$ School of Biomedical Sciences, University of Ulster, Coleraine, United Kingdom; the ${ }^{3}$ ARC Centre of Excellence in Vision Science, Research School of Biology, The Australian National University, Canberra, ACT, Australia; and the ${ }^{4}$ Department of Ophthalmology, Centre for Vision Research, Westmead Millennium Institute, University of Sydney, Sydney, NSW, Australia.

The Sydney Myopia Study (SMS) was supported by Grant 253732 from the Australian National Health \& Medical Research Council, the Westmead Millennium Institute, University of Sydney, and the Vision Cooperative Research Centre. The ARC Centre of Excellence in Vision Science (COE561903) supported contribution from Ian G. Morgan. The Northern Ireland Childhood Errors of Refraction (NICER) study was supported by The College of Optometrists, United Kingdom.

Submitted for publication January 22, 2012; revised April 15, 2012; accepted April 19, 2012.

Disclosure: A.N. French, None; L. O'Donoghue, None; I.G. Morgan, None; K.J. Saunders, None; P. Mitchell, None; K.A. Rose, None

Corresponding author: Kathryn A. Rose, Discipline of Orthoptics, Faculty of Health Sciences, University of Sydney, PO Box 170, Lidcombe, NSW, Australia, 1815; kathryn.rose@sydney.edu.au.
The prevalence of myopia varies significantly according to 1 location and ethnicity. ${ }^{1-6}$ School children from areas of East Asia have a particularly high prevalence of myopia ${ }^{1,7-13}$ as compared to other ethnic groups. ${ }^{4,14-27}$ There is debate about whether such variation results from genetic or environmental factors, ${ }^{28-32}$ but, while a family history of myopia adds an additional risk of developing myopia, ${ }^{33-36}$ ethnic differences may be attributed to cultural and behavioral differences, including attitudes to education. ${ }^{28,31}$

Comparison between age-matched children of Chinese ethnicity highlights the extent of variation with location. The Singapore Cohort Study of Risk Factors for Myopia (SCORM) sample of children (mean age, 13.7 years), has reported a prevalence of almost $70 \%$ in Singapore, ${ }^{37}$ while, in a similar age group from rural Chongqing, China, the prevalence is significantly lower at $21.1 \% .{ }^{38}$ Rates as low as $0.7 \%$ have been reported in 12- to 13-year-old children from Laos (Casson R, oral communication, September 2011), who are also part of the East Asian population genetic cluster. Comparison of refractive error in children of Chinese ancestry living in Sydney and Singapore has found that time spent outdoors is the dominant contributing factor to the almost 10-fold difference in prevalence of myopia between the two samples. ${ }^{2}$

Less is known about the variation in European Caucasian populations living in different geographic locations. ${ }^{18-27}$ The prevalence of myopia in Australian children appears to be particularly low. ${ }^{25,26}$ In comparison to the prevalence of myopia (11.9\%) in 12-year-old children from the Sydney Myopia Study (SMS), ${ }^{25}$ data from other sites have reported higher levels of myopia, ranging from $12.8 \%$ in Poland, ${ }^{24}$ through $18.3 \%$ in the United States, ${ }^{35} 29.4 \%$ in the United Kingdom, ${ }^{21}$ and $49.7 \%$ in Sweden. ${ }^{23}$ Such comparisons are difficult because of methodologic differences between studies, and to date no study, using similar methods, has directly compared the distribution of refractive error in populations of European Caucasian ethnicity living in different geographic locations.

The Northern Ireland Childhood Errors of Refraction (NICER) study has investigated a predominantly Caucasian sample of 6- to 7-year-old and 12- to 13-year-old children living in Northern Ireland, which is well matched in age and ethnicity to the European Caucasian children from the SMS study. The present study therefore compared refractive errors and ocular biometric parameters in these two population samples.

\section{Methods}

\section{Population}

Two population-based samples of 6- to 7-year-old and 12- to 13-year-old children were used from the SMS (2003-2005) and the NICER (2006- 
2008) studies. Both studies were school based and used a stratified random cluster design. The study area was organized into socioeconomic strata from government supplied data: quartiles in NICER (provided in the public domain by Northern Ireland Statistics and Research Agency: http://www.nisra.gov.uk/) and deciles in SMS (provided in the public domain by the Australian Bureau of Statistics: http://www.abs.gov.au/census). From each stratum, schools were randomly selected to ensure a representative sample was obtained. The participation rate was $79 \%$ and $75 \%$ in the SMS study and $57 \%$ and $60 \%$ in the NICER study for the 6- to 7 -year-old and 12 - to 13 -year-old age groups, respectively. These methodologies have been reported previously. 39,40

In the SMS study, children's ethnicity was determined by the selfidentified ethnic origin of both parents, using ethnic categories consistent with the Australian Standard Classification of Cultural and Ethnic Groups. ${ }^{41}$ These categories align with modern knowledge of human population genetic clusters. ${ }^{42}$ In the NICER study, ethnicity was assessed by the study coordinator and confirmed by parental questionnaire. Both study populations were predominantly European Caucasian at both ages 6 to 7 and 12 to 13 years (SMS, 63.7\% and $59.7 \%$, respectively; NICER, $98.2 \%$ and $98.8 \%$, respectively). For this analysis, only children who were of European Caucasian ethnicity were included.

\section{Procedures}

Written informed consent was obtained from parents or guardians of all children before examination. Ethical approval for SMS was obtained from the Human Research Ethics Committee, University of Sydney, the New South Wales Department of Education and Training, and the Catholic Education Office of the Archdiocese of Sydney. For the NICER study, approval was obtained from the University of Ulster's Research Ethics Committee. Both studies adhered to the tenets of the Declaration of Helsinki.

All children had a comprehensive eye examination including cycloplegic autorefraction. Cycloplegia was induced by cyclopentolate $1 \%$ following the instillation of a local anesthetic. In NICER, one drop of cyclopentolate was administered. In SMS, two drops were instilled in two cycles, 5 minutes apart, with the addition of tropicamide $1 \%$. Autorefraction was measured at least 20 minutes after the instillation of cycloplegic drops, by using a table-mounted autorefractor (model RKF1; Canon, Tokyo, Japan) in Sydney and a binocular open-field autorefractor (model SRW-5000; Shin-Nippon, Tokyo, Japan) in Northern Ireland. A comparison of results obtained from similar model autorefractors from these manufacturers using cycloplegia has shown that they are comparable for both spherical and cylindrical measures. ${ }^{43}$ Adequacy of cycloplegia was assessed before autorefraction, by pupil dilation $>6 \mathrm{~mm}$, and absence of pupil reaction to light and accommodative stimulus, in Sydney. In Northern Ireland, cycloplegia was assessed by absence of the pupillary light reflex and accommodative amplitude $<2 \mathrm{D}$.

Ocular biometry, including corneal radius of curvature (CR) and axial length (AL), was measured with a noncontact optical biometer (IOLMaster; Carl Zeiss Meditec Inc., Jena, Germany). The validity of AL measurements was assessed by a signal-to-noise ratio $\geq 2.0$, with a minimum of 3 (NICER) or 5 (SMS) measures taken. In both studies, three valid measurements of $\mathrm{CR}$ were obtained along the steepest (CR1) and flattest (CR2) meridians.

Height was measured with a free-standing height rod and weight was measured with Tanita digital scales (Tanita, Middlesex, United Kingdom). Body mass index (BMI) was calculated as weight in kilograms divided by height in meters squared.

A questionnaire was also administered at both sites, which provided information on parental factors including education level and parental myopia. In the SMS study, parental myopia was determined either by spectacle prescription or analysis of spectacleuse questions, as previously described and validated. ${ }^{44}$ In the NICER study, parents were asked whether they "wear spectacles" and if they are "short-sighted (needs spectacles to see far away)," with an affirmative response being used to classify them as myopic. Parental education was dichotomized into either tertiary or higher or lower education level for both studies.

\section{Definitions}

In both studies, refractive status was determined by the spherical equivalent refraction (SER), calculated as sphere $+1 / 2$ cylinder. Myopia was defined as a SER $\leq-0.50 \mathrm{D}$, hyperopia as $\geq+2.00 \mathrm{D}$, and refractive astigmatism as $\geq 1.00 \mathrm{D}$. Corneal radius of curvature is defined as the mean of the flattest and steepest corneal measures. The axial lengthcorneal radius ratio (AL/CR) was calculated as axial length, divided by the mean radius of curvature. There was a significant correlation between right and left eyes for SER, CR, and AL for both the 6- to 7-yearold age group (SMS: $r=0.91,0.98$, and 0.47 , respectively; NICER: $r=$ $0.90,0.97$, and 0.97 , respectively; all $P<0.0001$ ) and the 12 - to 13year-old age group (SMS: $r=0.87,0.37$, and 0.29 , respectively; NICER: $r$ $=0.89,0.98$, and 0.96 , respectively; all $P<0.0001$ ). As such, data were presented for the right eye only, with the exception of Figure 3, in which data from both eyes were pooled to examine the relationship between spherical refraction and astigmatism for individual eyes.

\section{Statistical Analyses}

Statistical analysis was performed with IBM SPSS Predictive Analytics Software (v. 19; IBM, New York City, NY). Analysis of variance (ANOVA) and $\chi^{2}$ analyses were used to determine differences in mean and prevalence values between the Sydney and Northern Ireland samples. Analysis of covariance (ANCOVA) was performed to account for the impact of anthropometry on ocular biometry. Measures of kurtosis and skewness were calculated for distributions. The Kolomogrov-Smirnov test was used to assess normality of distributions. To determine the impact of ocular biometric and anthropometric parameters on refraction, Pearson correlation coefficients were calculated and ageadjusted linear regression analysis was performed.

\section{Results}

\section{Distribution of Refractive Errors}

A total of 1497 children of European Caucasian ethnicity, aged 6 to 7 years, were included in the analysis: 1105 from Sydney and 392 from Northern Ireland. The 12- to 13-year-old age group sample included 2067 children in total, with 1406 from Sydney and 661 from Northern Ireland. Population characteristics for both samples are included in Table 1. Children living in Northern Ireland had a significantly higher prevalence of myopic, hyperopic, and astigmatic refractive errors in both the 6- to 7-year-old and the 12- to 13-year-old age groups than children living in Sydney. In addition, the children from Northern Ireland were significantly taller, heavier, and had a higher mean BMI than children in Sydney in both age samples (all $P<0.0001$ ).

The mean SER of 6- to 7-year-old children from Sydney and Northern Ireland was +1.40 and $+1.41 \mathrm{D}$, respectively $(P=$ $0.9)$. In contrast, 12- to 13-year-old children from Sydney had a significantly more hyperopic SER $(+0.83$ D) than children from Northern Ireland $(+0.66 \mathrm{D}, P=0.008)$. The distributions of SER for 6- to 7-year-old and 12- to 13-year-old children from Northern Ireland and Sydney were leptokurtic (Fig. 1). Kurtosis was significantly greater in Sydney (15.0) than Northern Ireland (7.2) in the younger group, while in the older group kurtosis was higher again in Sydney (19.54) than in Northern Ireland (5.86), where kurtosis appeared to have declined.

The distributions of cylinder power in the two locations were quite different (Fig. 2), with a much higher percentage of 

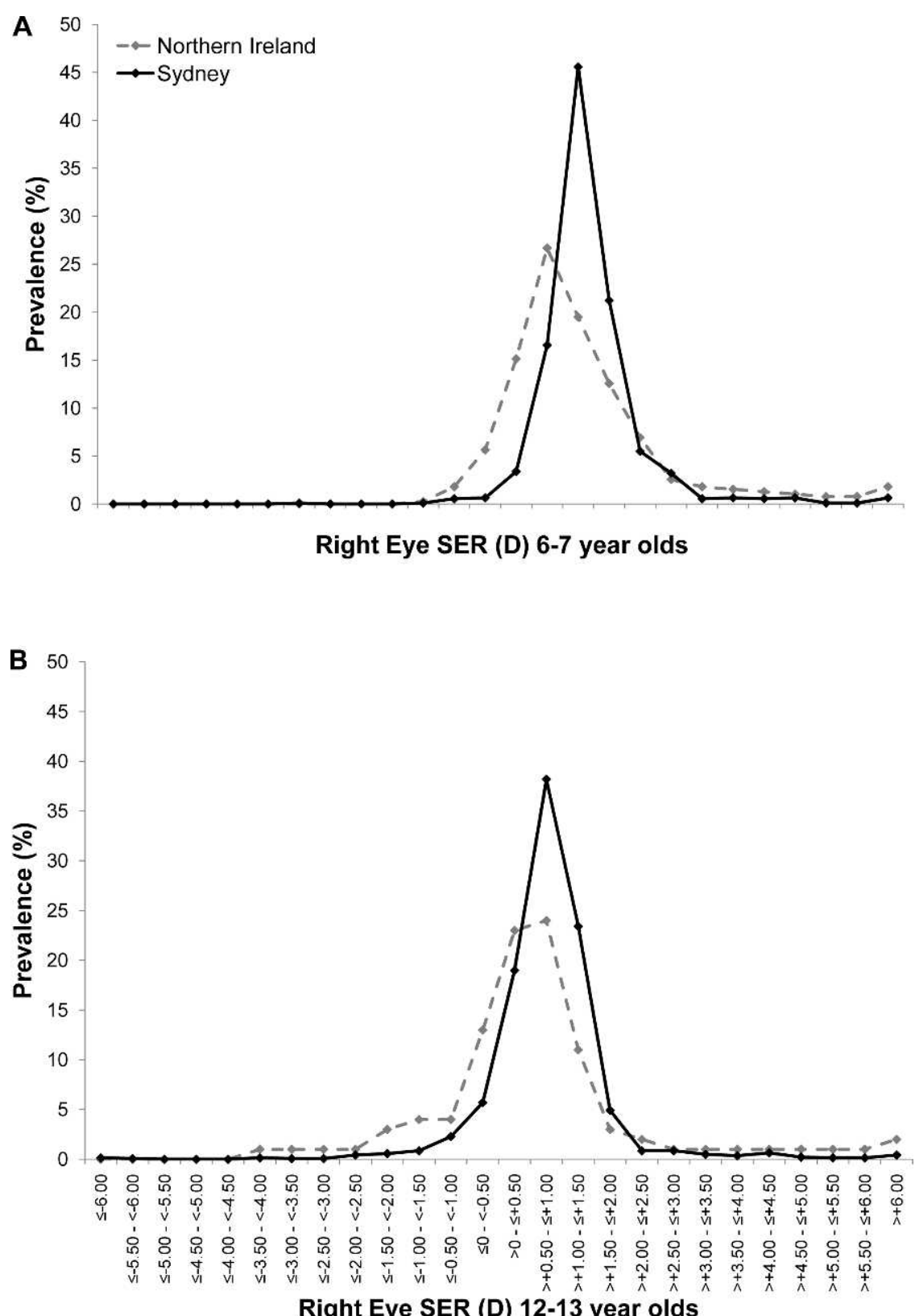

FiguRE 1. The distribution of refractive errors in European Caucasian children in Sydney and Northern Ireland. (A) Six- to 7-year-old age group. (B) Twelve- to 13-year-old age group.

children in Sydney having minimal levels of astigmatism than in Northern Ireland. Mean cylindrical refractive error was higher in Northern Ireland in the younger group $(-0.69 \mathrm{D}$ vs. -0.25 $\mathrm{D}, P<0.0001)$. This was also seen in the 12 - to 13 -year-old age group $(-0.64 \mathrm{D}$ vs. $-0.35 \mathrm{D}, P<0.0001)$. Figure 3 shows that for each level of refractive error, including emmetropia, there was markedly less astigmatism in children from Sydney than in those from Northern Ireland, for both age groups. This difference was statistically significant for children with emmetropic and hyperopic spherical refractions in both age groups (all $P<0.0001$ ). However, the difference in astigmatism between children from Northern Ireland and Sydney with myopia was not statistically significant at either 6 to 7 years of age $(P=0.1)$ or 12 to 13 years of age $(P=0.07)$, but the groups were small.

\section{Comparison of Parental Myopia and Education}

In the 6- to 7-year-old age group, the proportion of children with one or both of their parents myopic in Northern Ireland (49.4\%) was significantly greater than for Sydney children (38.6\%, $P=0.002$ ). However, there was no significant difference in the proportion of children with both parents myopic in Northern Ireland (7.6\%) and Sydney $(5.8 \%, P=0.3)$. For the 12- to 13-year-old age group, there was no significant difference between children from Northern Ireland and Sydney in the proportion of children with either one or both parents with myopia ( $40.9 \%$ and $37.4 \%$, respectively; $P=0.2$ ) or both parents with myopia (6.8\% and $4.7 \%$, respectively; $P=0.1$ ). The proportion of children whose parents (one or both) had completed some tertiary education was significantly lower in Northern Ireland than Sydney for both the 6- to 7-year-old 

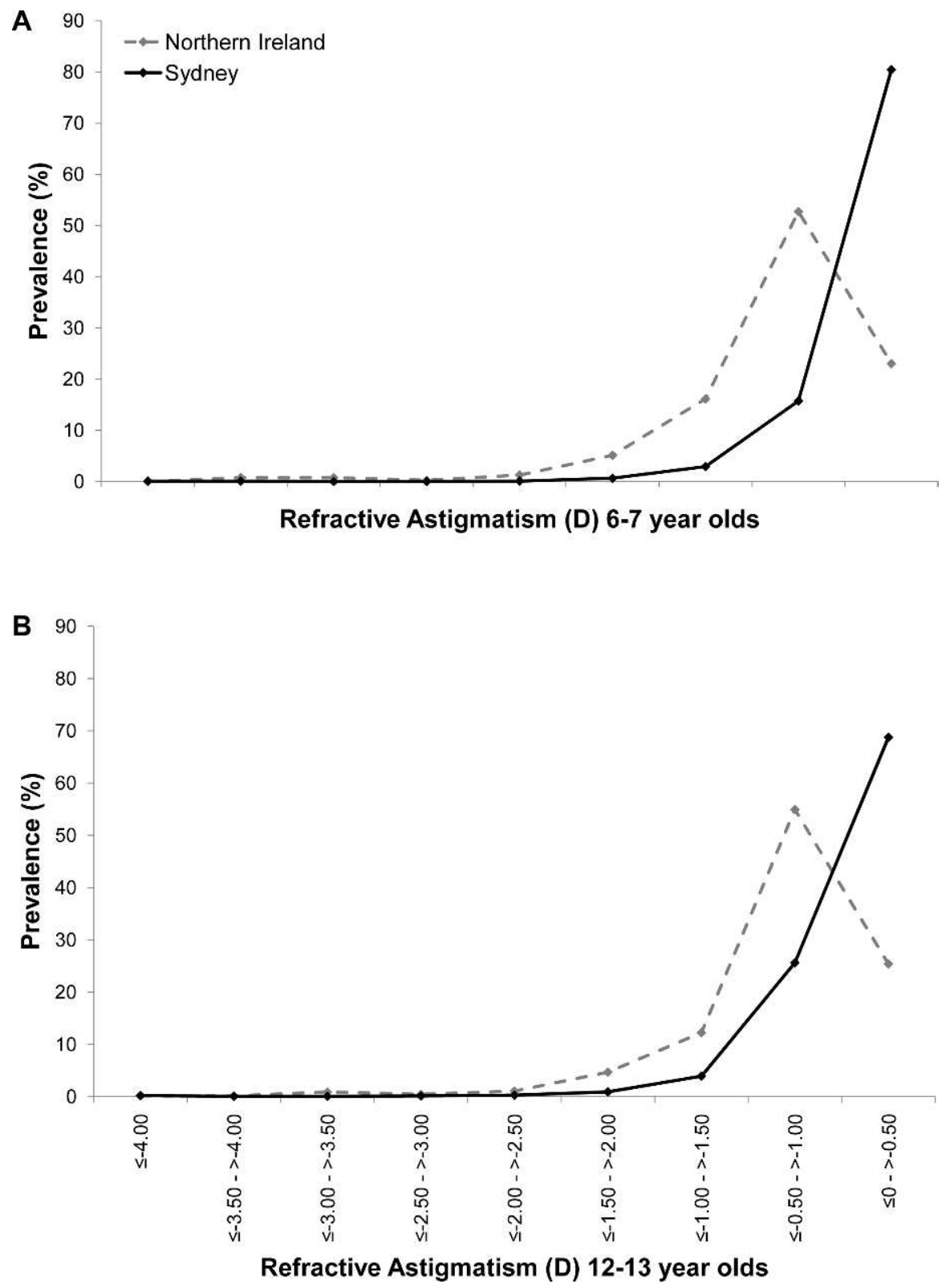

FiguRE 2. The distribution of refractive astigmatism in European Caucasian children in Sydney and Northern Ireland. (A) Six- to 7-year-old age group. (B) Twelve- to 13-year-old age group.

(52.1\% and $79.9 \%$, respectively; $P<0.0001)$ and the 12 - to $13-$ year-old children ( $49.0 \%$ and $71.5 \%$, respectively; $P<0.0001$ ).

A stepwise linear regression model using SER as the dependent variable and location, and parental myopia and parental education as covariates, was constructed. For the 6- to 7-year-old age group, parental myopia was the strongest determinant of refraction and alone produced an $r^{2}$ of 0.018 . Addition of location to the model significantly increased $r^{2}$ to $0.025(P=0.005)$, with both variables remaining significant. Parental education was not significant on univariate analysis $(P$ $=0.8)$ and its addition to the model did not significantly change $r^{2}(P=0.7)$. Similarly, in the 12 - to 13 -year-old age group, parental myopia alone produced an $r^{2}$ of 0.033 ; with addition of location, the $r^{2}$ value significantly increased to $0.042(P<$ 0.0001 ) and both remained significant. Again, addition of parental education did not significantly increase the strength of the model $(P=0.3)$.

\section{Comparison of Ocular Biometry}

Following adjustment for the difference in height between sites, children in Northern Ireland had a shorter mean axial length at 6 to 7 years of age $(P<0.0001)$ and a longer axial length at 12 to 13 years of age $(P<0.0001)$ than did Sydney children (Table 2). The AL/CR ratio was not significantly different in 6- to 7-year-old children from Northern Ireland (2.9) and Sydney (2.9, $P=0.08)$; however, it was greater in children from Sydney (2.99) than in those from Northern Ireland (2.97, $P<0.0001)$ at age 12 to 13 years. Corneal radius was significantly larger in children from Northern Ireland both at ages 6 to 7 years $(P<0.0001)$ and 12 to 13 years $(P<$ $0.0001)$.

The AL/CR ratio was leptokurtic in both Northern Ireland and Sydney in both age groups (Table 2). AL was normally distributed in the 6- to 7-year-olds from both Northern Ireland and Sydney and in 12- to 13-year-olds from Sydney. However, 

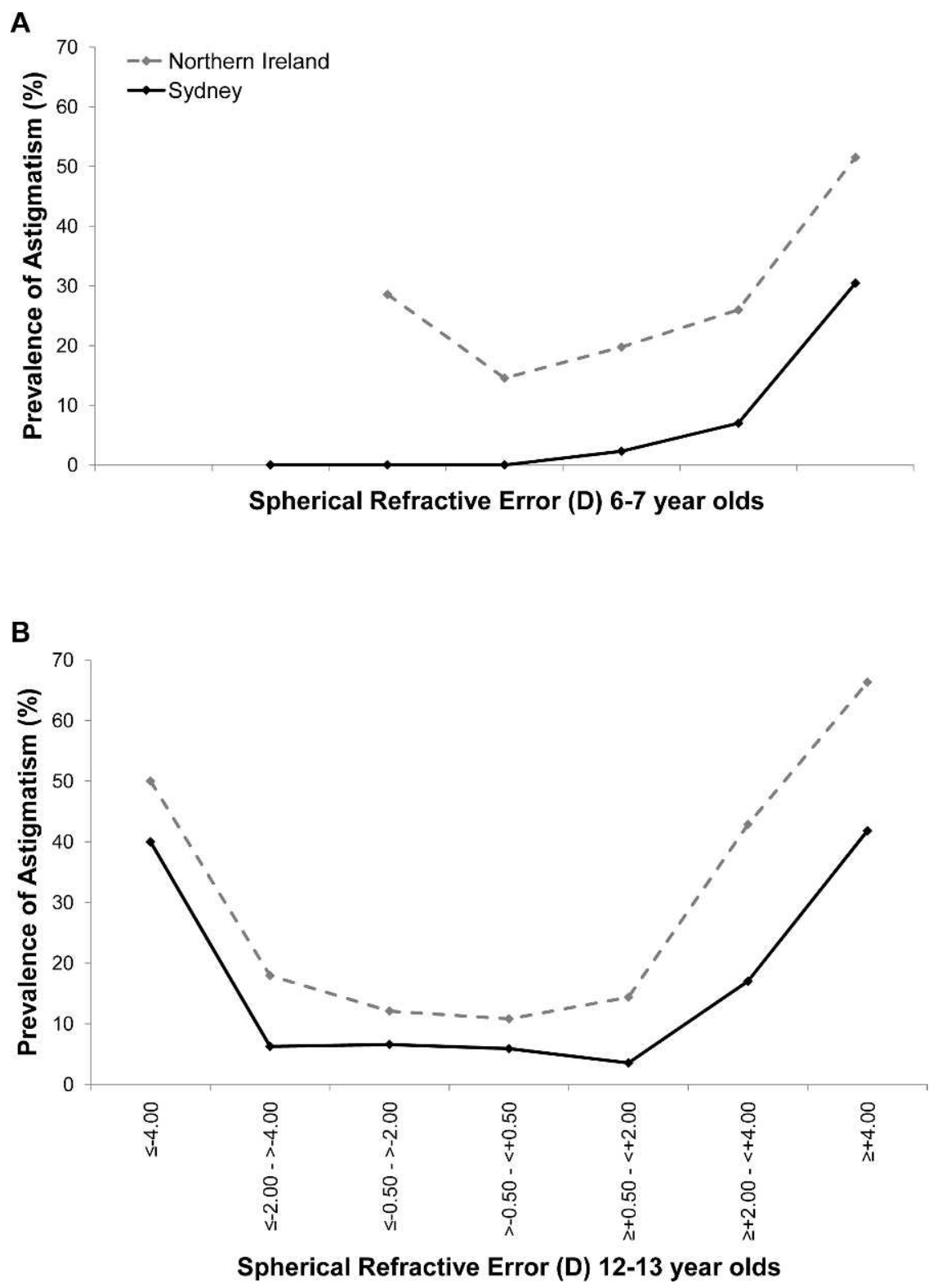

Figure 3. The prevalence of significant refractive astigmatism, according to spherical refraction of European Caucasian children living in Northern Ireland and Sydney, pooled for both eyes. (A) Six- to 7-year-old age group. (B) Twelve- to 13-year-old age group.

the distribution of $\mathrm{AL}$ in 12- to 13-year-olds from Northern Ireland showed some kurtosis (kurtosis $=1.2$ )

There was a significant negative correlation between AL and SER in both Northern Ireland and Sydney at ages 6 to 7 years and 12 to 13 years (Tables 3 and 4, respectively). This relationship remained strong in age-adjusted regression analysis. There was an even stronger negative correlation between AL/CR and SER in Northern Ireland and Sydney at both ages, which also remained significant after adjustment for age. A small but significant positive relationship was present between CR and SER in Northern Ireland at ages 6 to 7 years and 12 to 13 years. This relationship was also evident in children from Sydney at age 12 to 13 years, but not at age 6 to 7 years.

\section{Comparison of Anthropometry}

At age 6 to 7 years there was no significant relationship between SER and anthropometric measures (Table 3). At age 12 to 13 years there was a small but significant inverse correlation between height and SER in both Northern Ireland and Sydney (Table 4). On regression analysis this relationship remained significant in Sydney $\left(r^{2}=0.02, P<0.0001\right)$, with each $1-\mathrm{cm}$ increase in height associated with a decrease in refraction of $-0.02 \mathrm{D}$. However, this relationship was no longer significant in Northern Ireland $\left(r^{2}=0.01, P=0.09\right)$. A similar small, but significant, association was present between weight and SER in Sydney and this remained significant after adjustment for age $\left(r^{2}=0.009, P=0.004\right)$. This relationship was not evident in the Northern Ireland sample. The small positive correlation between BMI and SER in children from Northern Ireland was not significant after adjustment for age.

\section{Relationship between Anthropometry and Ocular Biometry}

Height was significantly correlated with AL in both Northern Ireland and Sydney for both age samples (6-7 years of age: $r=$ 
TABLE 1. Characteristics of 6- to 7-Year-Old and 12- to 13-Year-Old European Caucasian Children Living in Northern Ireland and Sydney

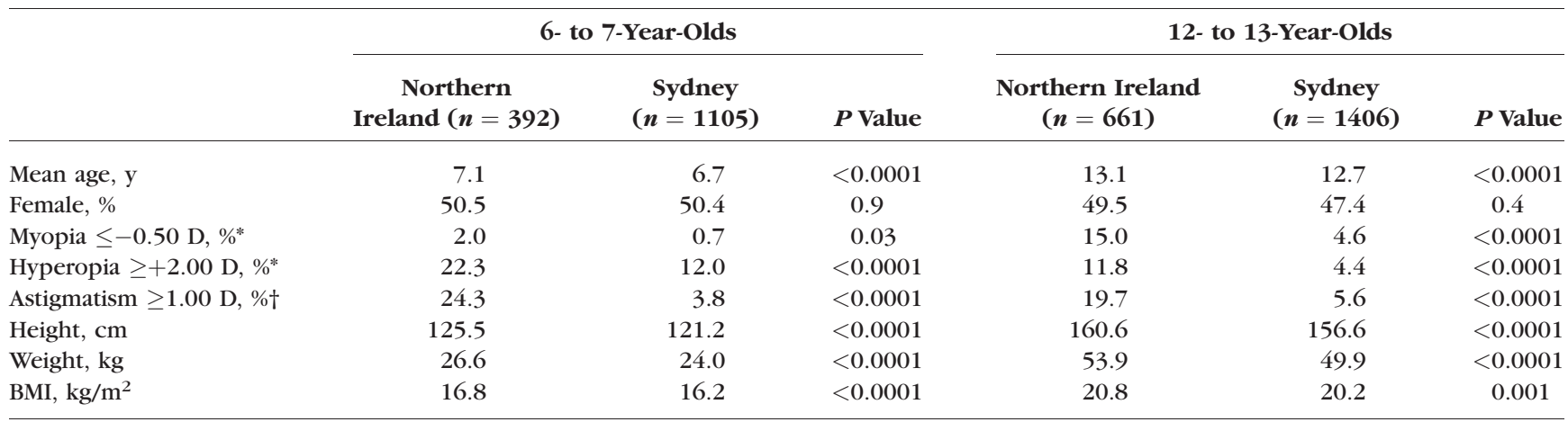

* Based on SER of the right eye.

$\dagger$ Based on right eye prevalence.

$0.2, P<0.0001$ and $r=0.3, P<0.0001$, respectively; $12-13$ years of age: $r=0.2, P<0.0001$ and $r=0.1, P<0.0001$, respectively). There was also a small but significant correlation between height and CR in both Northern Ireland and Sydney (6-7 years of age: $r=0.1, P=0.01$ and $r=0.2, P<0.0001$, respectively; $12-13$ years of age, $r=0.1, P=0.006$ and $r=0.08$, $P=0.004$, respectively). Height was also related to AL/CR ratio in 12- to 13-year-olds from Northern Ireland $(r=0.08, P=0.04)$ and Sydney $(r=0.1, P<0.0001)$ but not in 6- to 7-year-olds.

Greater weight was related to longer AL in Northern Ireland and Sydney at age 6 to 7 years $(r=0.2$ and 0.2 , respectively; $P$ $<0.0001$ ), but only in Sydney for the 12- to 13-year-old age group sample $(r=0.1, P<0.0001)$. Similarly, weight was significantly related to CR in 6- to 7-year-olds in both Northern Ireland and Sydney ( $r=0.2$ and 0.1 , respectively; $P<0.0001)$, but only in Sydney for 12- to 13-year-olds ( $r=0.1, P=0.02$ ). $\mathrm{AL} / \mathrm{CR}$ ratio was significantly correlated with weight in the Sydney samples (6-7 years of age: $r=0.1, P=0.03 ; 12-13$ years of age: $r=0.1, P=0.004)$ but not in children from Northern Ireland.

In 6- to 7-year-olds from Northern Ireland, BMI was correlated with AL $(r=0.1, P=0.05)$ and CR $(r=0.1, P=$ 0.01). In 6- to 7-year-olds from Sydney, BMI was not related to $\mathrm{AL}$ or CR. In 12- to 13-year-olds, BMI was significantly and positively correlated with AL in Sydney $(r=0.1, P=0.01)$ and negatively correlated in Northern Ireland $(r=-0.1, P=0.03)$. BMI was also negatively correlated with AL/CR ratio in Northern Ireland for 12 - to 13-year-olds $(r=-0.1, P=0.01)$, but not in Sydney.

\section{Discussion}

This comparison of age- and ethnicity-matched children of European Caucasian origin from the SMS and NICER studies has shown that the prevalence of myopia, hyperopia, and astigmatism is significantly higher in Northern Ireland than in Sydney in both 6- to 7-year-olds and 12- to 13-year-olds. The mean SER was similar in the two locations in the younger age group, but was significantly lower in Northern Ireland than in Sydney at the age of 12 to13 years, probably owing to a greater shift towards myopia with increasing age in Northern Ireland.

There are few comparable population-based studies on children of European Caucasian origin from other sites. The Aston Eye Study ${ }^{21}$ has reported a prevalence of myopia for 12to 13-year-old European Caucasian children in the United Kingdom of $29.4 \%$. The prevalence of myopia in Poland is $13.9 \%$ in urban children of this age, and $9.4 \%$ in children from rural areas. ${ }^{24}$ In white children aged 12 to13 years in the Collaborative Longitudinal Evaluation of Ethnicity and Refractive Error study, the prevalence is $23.8 \%$ (Mutti D, oral communication, September 2011), and the highest value reported for children of European origin is $49.7 \%$ at the age of 12 years in a school-based sample in Sweden. ${ }^{23}$ Thus, there is marked variation in the prevalence of refractive errors in European Caucasian children, just as there is in children of East Asian origin.

A major strength of this study is that the methods used in the two component studies were very similar, involving schoolbased recruitment, cycloplegic autorefraction, and IOLMaster measurements of biometry. As the protocol for cycloplegia was

TABLE 2. SER and Ocular Biometric Parameters in European Caucasian Children Living in Sydney and Northern Ireland

\begin{tabular}{|c|c|c|c|c|c|c|c|c|c|c|c|}
\hline & \multicolumn{5}{|c|}{ Northern Ireland } & \multicolumn{5}{|c|}{ Sydney } & \multirow[b]{2}{*}{$\boldsymbol{P}^{*}$} \\
\hline & Mean & Range & Kurtosis & Skewness & K-S & Mean & Range & Kurtosis & Skewness & K-S & \\
\hline \multicolumn{12}{|l|}{ 6- to 7 -year-olds } \\
\hline SER, D & +1.41 & -1.13 to 9.00 & 7.2 & 2.2 & $<0.0001$ & +1.40 & -3.22 to 8.50 & 15.0 & 2.5 & $<0.0001$ & 0.9 \\
\hline Axial length, mm & 22.51 & 19.5 to 24.7 & 0.4 & -0.3 & 0.2 & 22.58 & 19.6 to 24.6 & 0.38 & -0.2 & 0.2 & $<0.0001$ \\
\hline Corneal radius, $\mathrm{mm}$ & 7.82 & 7.1 to 8.6 & -0.2 & 0.1 & 0.1 & 7.77 & 7.0 to 8.7 & -0.1 & 0.2 & 0.03 & $<0.0001$ \\
\hline $\begin{array}{l}\mathrm{AL} / \mathrm{CR} \text { ratio } \\
12 \text { - to } 13 \text {-year-olds }\end{array}$ & 2.88 & 2.5 to 3.1 & 1.4 & -0.8 & $<0.0001$ & 2.89 & 2.5 to 3.2 & 2.2 & -0.6 & $<0.0001$ & 0.08 \\
\hline SER, D & +0.66 & -5.63 to 10.75 & 5.86 & 1.16 & $<0.0001$ & +0.83 & -8.93 to 8.37 & 19.54 & 0.30 & $<0.0001$ & 0.008 \\
\hline Axial length, mm & 23.30 & 19.2 to 27.5 & 1.22 & -0.09 & 0.04 & 23.24 & 19.8 to 26.3 & 0.72 & 0.01 & 0.2 & $<0.0001$ \\
\hline Corneal radius, $\mathrm{mm}$ & 7.84 & 7.1 to 8.8 & 0.08 & 0.12 & 0.2 & 7.77 & 6.8 to 9.0 & 0.43 & 0.15 & 0.2 & $<0.0001$ \\
\hline $\mathrm{AL} / \mathrm{CR}$ ratio & 2.97 & 2.5 to 3.4 & 2.05 & -0.40 & $<0.0001$ & 2.99 & 2.7 to 3.4 & 2.82 & 0.08 & $<0.0001$ & $<0.0001$ \\
\hline
\end{tabular}

K-S, Kolmogorov-Smirnov test for normality.

* $P$ value refers to difference in mean between Northern Ireland and Sydney. When ocular biometry is compared, $P$ values are adjusted for height. 
TABLE 3. The Association of Ocular Biometric and Anthropometric Parameters and SER in 6- to 7-Year-Old European Caucasian Children Living in Northern Ireland and Sydney

\begin{tabular}{|c|c|c|c|c|c|c|}
\hline & \multicolumn{3}{|c|}{ Northern Ireland } & \multicolumn{3}{|c|}{ Sydney } \\
\hline & $\begin{array}{c}\text { Pearson } \\
\text { Correlation }\end{array}$ & $\beta$ Coefficient (CI)* & Model $\boldsymbol{R}^{2 *}$ & $\begin{array}{c}\text { Pearson } \\
\text { Correlation }\end{array}$ & $\beta$ Coefficient $(\mathrm{CI})^{*}$ & Model $\boldsymbol{R}^{2 *}$ \\
\hline Axial length, mm & $-0.5 \dagger$ & $-0.99(-1.1$ to -0.8$) \dagger$ & 0.3 & $-0.4 \dagger$ & $-0.51(-0.6$ to -0.4$) \dagger$ & 0.2 \\
\hline Corneal radius, $\mathrm{mm}$ & $0.2 \ddagger$ & $0.87(0.3$ to 1.4$) \ddagger$ & 0.03 & 0.04 & $0.14(-0.05$ to 0.3$)$ & 0.002 \\
\hline $\mathrm{AL} / \mathrm{CR}$ ratio & $-0.8 \dagger$ & $-12.7(-13.7$ to -11.7$) \dagger$ & 0.6 & $-0.7 \dagger$ & $-0.9(-9.2$ to -8.0$) \dagger$ & 0.4 \\
\hline Height, $\mathrm{cm}$ & 0.06 & $0.02(-0.007$ to 0.05$)$ & 0.005 & -0.01 & $-0.003(-0.01$ to 0.006$)$ & 0.001 \\
\hline Weight, $\mathrm{kg}$ & 0.08 & $0.03(-0.005$ to 0.06$)$ & 0.007 & -0.003 & $-0.002(-0.01$ to 0.01$)$ & 0 \\
\hline BMI, $\mathrm{kg} / \mathrm{m}^{2}$ & 0.06 & $0.04(-0.03$ to 0.1$)$ & 0.004 & 0.005 & $0.002(-0.02$ to 0.03$)$ & 0 \\
\hline
\end{tabular}

CI, 95\% Confidence Intervals.

* In regression model, SER was the dependant variable, with each biometric or anthropometric variable as an explanatory variable; all analyses were adjusted for age.

† Significant to the level of $P \leq 0.001$.

‡ Significant to the level of $P \leq 0.05$.

slightly different between the two studies, with both using cyclopentolate $1 \%$ but with the addition of tropicamide $1 \%$ in Sydney, this could be a potential source of variation in refractive errors between Northern Ireland and Sydney. However, previous research has shown that there is no significant difference in the cycloplegic effect obtained from cyclopentolate alone versus a combination of cyclopentolate and tropicamide in children with light irises, ${ }^{45}$ and adequacy of cycloplegia was rigorously assessed in both studies before refraction. Additionally, the differences in the prevalence of refractive errors noted between Sydney and Northern Ireland are not consistent with a difference in the adequacy of cycloplegia between sites, because there were more cases of myopia and hyperopia in Northern Ireland and fewer cases of myopia and hyperopia in Sydney, whereas inadequate cycloplegia causes overestimation of myopia and underestimation of hyperopia.

There was also an average 6-month age difference between the two locations. While this is statistically significant, it is of a magnitude that is unlikely to be responsible for the significant differences in refraction between sites. Another difference between the population samples is the fact that while both are of European Caucasian ethnicity, the population of Northern Ireland is overwhelmingly Anglo-Celtic in origin, whereas that of Sydney is more diverse, with a proportion having ancestry from Northern, Southern, and Eastern Europe. The European Caucasian population in Sydney is nevertheless predominantly Anglo-Celtic in origin.
As the differences in refractive errors between Northern Ireland and Sydney are so pronounced, a possible explanation is that the process of emmetropization is different in each location. To investigate this, observations need to be interpreted within the framework of current knowledge about refractive development in children. Briefly, children are predominantly hyperopic at birth, with a normal distribution of refractive errors. ${ }^{46,47}$ In the first year or two after birth, the cornea stabilizes, ${ }^{48}$ but the refractive distribution becomes tighter, with reductions in both myopia and hyperopia, leading to substantial leptokurtosis with a mean SER that is approximately between 1 and $2 \mathrm{D}^{46,47}$ This appears to involve matching the axial length of the eye to the corneal radius, which produces a leptokurtic distribution of the AL/CR ratio by the age of 6 to 7 years. ${ }^{26}$ After this time, axial length continues to increase, and hyperopic errors are further reduced, while myopic errors increase in prevalence. ${ }^{48,49}$

In both Northern Ireland and Sydney, the distributions of SER were leptokurtic, while AL and CR were both normally distributed. In addition, there were strong correlations of $\mathrm{AL}$ and AL/CR with SER in both locations, but the correlations of CR with SER were much lower, although statistically significant. These features are commonly seen during childhood, suggesting that the process of emmetropization is similar in Northern Ireland and Sydney and that the different refractive outcomes result from relatively subtle modulation of a common emmetropization process.

TABLE 4. The Association of Ocular Biometric and Anthropometric Parameters and SER in 12- to 13-Year-Old European Caucasian Children Living in Northern Ireland and Sydney

\begin{tabular}{|c|c|c|c|c|c|c|}
\hline & \multicolumn{3}{|c|}{ Northern Ireland } & \multicolumn{3}{|c|}{ Sydney } \\
\hline & $\begin{array}{c}\text { Pearson } \\
\text { Correlation }\end{array}$ & $\beta$ Coefficient (CI)* & Model $\boldsymbol{R}^{2 *}$ & $\begin{array}{c}\text { Pearson } \\
\text { Correlation }\end{array}$ & $\beta$ Coefficient (CI)* & Model $\boldsymbol{R}^{2 *}$ \\
\hline Axial length, mm & $-0.68 \dagger$ & $-1.3(-1.35$ to -1.15$) \dagger$ & 0.47 & $-0.32 \dagger$ & $-0.4(-0.47$ to -0.34$) \dagger$ & 0.10 \\
\hline Corneal radius, $\mathrm{mm}$ & $0.09 \ddagger$ & $0.6(0.11$ to 1.11$) \ddagger$ & 0.02 & $0.07 \ddagger$ & $0.3(0.07$ to 0.49$) \ddagger$ & 0.08 \\
\hline $\mathrm{AL} / \mathrm{CR}$ ratio & $-0.86 \dagger$ & $-13.9(-14.55$ to -13.26$) \dagger$ & 0.73 & $-0.70 \dagger$ & $-8.9(-9.39$ to -8.43$) \dagger$ & 0.49 \\
\hline Height, $\mathrm{cm}$ & $-0.09 \ddagger$ & $-0.02(-0.03$ to 0.003$)$ & 0.01 & $-0.13 \dagger$ & $-0.02(-0.02$ to -0.009$) \dagger$ & 0.02 \\
\hline Weight, kg & 0.03 & $0.007(-0.004$ to 0.018$)$ & 0.008 & $-0.08+$ & $-0.006(-0.011$ to -0.002$) \ddagger$ & 0.009 \\
\hline BMI, $\mathrm{kg} / \mathrm{m}^{2}$ & $0.08 \ddagger$ & $0.04(0.005$ to 0.08$)$ & 0.013 & -0.03 & $-0.009(-0.02$ to 0.005$)$ & 0.004 \\
\hline
\end{tabular}

CI, 95\% Confidence Intervals.

* In regression model, SER was the dependant variable, with each biometric or anthropometric variable as an explanatory variable; all analyses were adjusted for age.

† Significant to the level of $P \leq 0.001$

‡ Significant to the level of $P \leq 0.05$. 
The children from Northern Ireland were significantly taller, heavier, and had higher BMI than the children in Sydney at both ages. Given the difference in stature, the correlations between SER and anthropometric measures were investigated. While the literature is far from consistent, ${ }^{50-53}$ some studies have shown that greater height is associated with a more myopic refraction. ${ }^{54-57}$ Statistically significant associations of SER with height were detected in the 12- to 13-year-olds, but not in the younger group, at both sites, but regression analysis suggested that the effects were very small and could not account for the differences in refraction between Northern Ireland and Sydney. The relationship between axial length and height has been well documented, ${ }^{50,54,58}$ but the correlations of SER with height were much lower than those of axial length with height, showing that emmetropization largely eliminated any relationship between height and refraction in both locations.

The major feature of these data is that at both the ages of 6 to 7 years and 12 to 13 years, there are fewer cases of myopia and fewer cases of hyperopia in Sydney than in Northern Ireland. Emergence of myopic refractive errors with growth and associated axial elongation throughout childhood often coincides with a parallel decrease in hyperopic refractive errors. $^{7-9,15,21}$ That this was not the case in Northern Ireland implies that there may be separate regulation of axial elongation leading to myopia as compared to axial elongation leading to reduction in hyperopia, as appears to be the case earlier in development. ${ }^{46,47}$

While little is known about why some children remain significantly hyperopic, the development of myopia may be associated with increased engagement in education. ${ }^{59-67}$ However, surveys carried out by the Organisation for Economic Co-operation and Development suggest that educational outcomes are higher in Australia ${ }^{68}$ than in the United Kingdom, including Northern Ireland. ${ }^{69}$ In support of this, our results showed that the proportion of parental tertiary education was significantly lower in Northern Ireland than Sydney.

Previous studies have also reported a strong link between parental myopia and the development of myopia in children. ${ }^{33,35}$ While parental myopia was again a strong predictor of refraction in these two samples of children, this factor only accounted for between $2 \%$ and $3 \%$ of variation in refractive error in pooled data. In general, the differences in levels of parental myopia between the two sites were small and cannot account for the considerable differences in myopia prevalence between sites.

Another factor that has been documented is the protective effect against the development of myopia of increased time spent outdoors, ${ }^{34,70-73}$ which has been shown to be mediated by increased release of retinal dopamine by bright light in animal models. ${ }^{74,75}$ A previous analysis of Chinese children growing up in Singapore and Sydney has shown that the major factor associated with the large difference in prevalence of myopia is time spent outdoors. ${ }^{2}$ The authors do not currently have data on time spent outdoors from Northern Ireland and Sydney, but comparable data will be available from phase 2 of the NICER study, which is reexamining participants three years after their initial measures. However, weather records suggest that climate in Northern Ireland may place an upper limit on light exposures of 2 hours of sunlight per day for 4 months of the year, ${ }^{76}$ which is probably below that required for protection, ${ }^{34,70}$ whereas daily sunshine duration is typically 6 to 7 hours year round in Sydney. ${ }^{77}$ National Aeronautics and Space Administration data also suggest that illumination is generally lower in Northern Ireland than in Sydney. ${ }^{78}$ These two aspects of light exposure may contribute to the higher levels of myopia in Northern Ireland, and the difference in availability of bright sunlight exposure in the two locations makes such a hypothesis plausible. It will be tested through the collection of individual data on time spent outdoors in future follow-up studies.

There are many other differences between the two sites. The authors have dealt with four (educational and outdoor exposures in the children and parental myopia and education), because there is substantial evidence that they have a major impact on the development of myopia, and there are plausible mechanisms for their effects. The evidence for other factors is weaker. Diet has been suggested as a risk factor for myopia, with a plausible mechanism proposed, ${ }^{79}$ but in Singapore children, while diet does appear to influence axial length, it has no effect on refraction, presumably owing to effective emmetropization. ${ }^{80}$ Even extreme undernutrition, resulting in overall stunting, does not appear to influence refractive development. ${ }^{81}$ The authors do not have systematic data on this very complex factor, but the available evidence suggests that it is unlikely to explain the differences. Population density may also be important, as suggested in two previous studies. ${ }^{82,83}$ Both articles suggest that the prevalence of myopia is higher when the population density is high, but the data from China ${ }^{83}$ show that, while the association is statistically significant, the impact of population density is very small. This is also the case for the data from Sydney. ${ }^{82}$ It should also be noted that the SMS sample is predominantly urban, while the NICER study surveyed urban and rural areas; yet the prevalence of myopia was higher in Northern Ireland. The population density is 130 persons $/ \mathrm{km}^{2}$ for Northern Ireland, ${ }^{84}$ compared to 2058 persons $/ \mathrm{km}^{2}$ in Sydney, ${ }^{85}$ suggesting that population density is unlikely to explain the higher prevalence in Northern Ireland.

The prevalence of astigmatism is also much lower in Sydney than in Northern Ireland. One possible explanation for the difference is based on the higher prevalence of ametropia in Northern Ireland, which has been previously reported to be related to a higher prevalence of astigmatism. ${ }^{86-88}$ This can be ruled out, since Figure 3 shows that for emmetropia or any given level of ametropia, there is less astigmatism in Sydney than in Northern Ireland. There is some evidence for the presence of a developmental process by which refractive astigmatism is reduced relative to corneal astigmatism. ${ }^{86,87}$ While this process is poorly characterized, the higher levels of astigmatism in Northern Ireland, which are consistent with corneal measures, ${ }^{88}$ indicate that this process may be less effective in Northern Ireland. It is to be noted that levels of astigmatism also vary between other populations of European ancestry. ${ }^{89,90}$ Further work is required to fully explore the mechanisms underlying the control of the development of astigmatism.

In summary, this comparison of refractive status in two ageand ethnicity-matched school-based representative samples of children of European ancestry from Northern Ireland and Sydney, using common methodology, showed that children in Northern Ireland had a significantly higher prevalence of both myopia and hyperopia, as well as astigmatism, at both ages 6 to 7 years and 12 to 13 years, than did children in Sydney. The authors suggest that the differences in the development of myopia may be explained by the protective effect of time spent outdoors in bright light, but the mechanisms that account for the disparities in hyperopia and astigmatism are currently unclear.

\section{Acknowledgments}

The authors thank Alicja Rudnicka and Chris Owen for their contribution to the design of the sampling frame for the NICER study. 


\section{References}

1. Saw SM, Goh PP, Cheng A, Shankar A, Tan DTH, Ellwein LB. Ethnicity-specific prevalences of refractive errors vary in Asian children in neighbouring Malaysia and Singapore. $\mathrm{Br} \mathrm{J}$ Ophthalmol. 2006;90:1230-1235.

2. Rose KA, Morgan IG, Smith W, Burlutsky G, Mitchell P, Saw SM. Myopia, lifestyle, and schooling in students of Chinese ethnicity in Singapore and Sydney. Arch Ophthalmol. 2008; 126:527-530.

3. Xu L, Li J, Cui T, et al. Refractive error in urban and rural adult Chinese in Beijing. Ophthalmology. 2005;112:1676-1683.

4. Dandona R, Dandona L, Srinivas M, et al. Refractive error in children in a rural population in India. Invest Ophthalmol Vis Sci. 2002; 43:615-622.

5. Garner LF, Owens H, Kinnear RF, Frith MJ. Prevalence of myopia in Sherpa and Tibetan children in Nepal. Optom Vis Sci. 1999;76:282-285.

6. Zhan MZ, Saw SM, Hong RZ, et al. Refractive errors in Singapore and Xiamen, China-a comparative study in school children aged 6 to 7 years. Optom Vis Sci. 2000;77:302-308.

7. He M, Zeng J, Liu Y, Xu J, Pokharel GP, Ellwein LB. Refractive error and visual impairment in urban children in Southern China. Invest Ophthalmol Vis Sci. 2004;45:793-799.

8. Zhao J, Pan X, Sui R, Munoz SR, Sperduto RD, Ellwein LB. Refractive error study in children: results from Shunyi District, China. Am J Opbthalmol. 2000;129:427-435.

9. Goh P-P, Abqariyah Y, Pokharel GP, Ellwein LB. Refractive error and visual impairment in school-age children in Gombak District, Malaysia. Ophthalmology. 2005;112:678-685.

10. Quek TP, Chua CG, Chong CS, et al. Prevalence of refractive errors in teenage high school students in Singapore. Ophthalmic Physiol Opt. 2004;24:47-55.

11. Fan DS, Lam DS, Lam RF, et al. Prevalence, incidence, and progression of myopia of school children in Hong Kong. Invest Ophthalmol Vis Sci. 2004;45:1071-1075.

12. Lin LL, Shih YF, Hsiao CK, Chen CJ. Prevalence of myopia in Taiwanese schoolchildren: 1983 to 2000. Ann Acad Med Singapore. 2004;33:27-33.

13. Wu MM, Edwards MH. The effect of having myopic parents: an analysis of myopia in three generations. Optom Vis Sci. 1999; 76:387-392.

14. Murthy GVS, Gupta SK, Ellwein LB, et al. Refractive error in children in an urban population in New Delhi. Invest Ophthalmol Vis Sci. 2002;43:623-631.

15. Maul E, Barroso S, Munoz SR, Sperduto RD, Ellwein LB. Refractive error study in children: results from La Florida, Chile. Am J Ophthalmol. 2000;129:445-454.

16. Pokharel GP, Negrel AD, Munoz SR, Ellwein LB. Refractive error study in children: results from Mechi Zone, Nepal. Am J Ophthalmol. 2000;129:436-444.

17. Naidoo KS, Raghunandan A, Mashige KP, et al. Refractive error and visual impairment in African children in South Africa. Invest Ophthalmol Vis Sci. 2003;44:3764-3770.

18. Grönlund MA, Andersson S, Aring E, Hård A-L, Hellström A. Ophthalmological findings in a sample of Swedish children aged 4-15 years. Acta Ophthalmol Scand. 2006;84:169-176.

19. Czepita D, Żejmo M, Mojsa A. Prevalence of myopia and hyperopia in a population of Polish schoolchildren. Ophthalmic Physiol Opt. 2007;27:60-65.

20. O'Donoghue L, McClelland JF, Logan NS, Rudnicka AR, Owen CG, Saunders KJ. Refractive error and visual impairment in school children in Northern Ireland. Br J Ophthalmol. 2010; 94:1155-1159.

21. Logan NS, Shah P, Rudnicka AR, Gilmartin B, Owen CG. Childhood ethnic differences in ametropia and ocular biometry: the Aston Eye Study. Ophthalmic Physiol Opt. 2011;31:550-558.

22. Rudnicka AR, Owen CG, Nightingale CM, Cook DG, Whincup $\mathrm{PH}$. Ethnic differences in the prevalence of myopia and ocular biometry in 10- and 11-year-old children: The Child Heart and Health Study in England (CHASE). Invest Ophthalmol Vis Sci. 2010;51:6270-6276.

23. Villarreal MG, Ohlsson J, Abrahamsson M, Sjöström A, Sjöstrand J. Myopisation: the refractive tendency in teenagers-prevalence of myopia among young teenagers in Sweden. Acta Ophthalmol Scand. 2000;78:177-181.

24. Czepita D, Mojsa A, Zejmo M. Prevalence of myopia and hyperopia among urban and rural schoolchildren in Poland. Ann Acad Med Stetin. 2008;54:17-21.

25. Ip JM, Huynh SC, Robaei D, et al. Ethnic differences in refraction and ocular biometry in a population-based sample of 11-15-year-old Australian children. Eye (Lond). 2008;22: 649-656.

26. Ojaimi E, Rose KA, Morgan IG, et al. Distribution of ocular biometric parameters and refraction in a population-based study of Australian children. Invest Ophthalmol Vis Sci. 2005; 46:2748-2754.

27. Zadnik K, Manny RE, Yu JA, et al. Ocular component data in schoolchildren as a function of age and gender. Optom Vis Sci. 2003;80:226-236.

28. Morgan I, Rose K. How genetic is school myopia? Prog Retin Eye Res. 2005;24:1-38.

29. Rose KA, Morgan IG, Smith W, Mitchell P. High heritability of myopia does not preclude rapid changes in prevalence. Clin Exp Ophthalmol. 2002;30:168-172.

30. Hornbeak DM, Young TL. Myopia genetics: a review of current research and emerging trends. Curr Opin Ophthalmol. 2009; 20:356-362.

31. Wojciechowski R. Nature and nurture: the complex genetics of myopia and refractive error. Clin Genet. 2011;79:301-320.

32. Mutti DO. Hereditary and environmental contributions to emmetropization and myopia. Optom Vis Sci. 2010;87:255259.

33. Ip JM, Huynh SC, Robaei D, et al. Ethnic differences in the impact of parental myopia: findings from a population-based study of 12-year-old Australian children. Invest Ophthalmol Vis Sci. 2007; 48:2520-2528.

34. Jones LA, Sinnott LT, Mutti DO, Mitchell GL, Moeschberger ML, Zadnik K. Parental history of myopia, sports and outdoor activities, and future myopia. Invest Ophthalmol Vis Sci. 2007; 48:3524-3532.

35. Mutti DO, Mitchell GL, Moeschberger ML, Jones LA, Zadnik K. Parental myopia, near work, school achievement, and children's refractive error. Invest Ophthalmol Vis Sci. 2002;43: 3633-3640.

36. Jones-Jordan LA, Sinnott LT, Manny RE, et al. Early childhood refractive error and parental history of myopia as predictors of myopia. Invest Ophthalmol Vis Sci. 2010;51:115-121.

37. Dirani M, Tong L, Gazzard G, et al. Outdoor activity and myopia in Singapore teenage children. Br J Ophthalmol. 2009; 93:997-1000.

38. Pi LH, Chen L, Liu Q, et al. Refractive status and prevalence of refractive errors in suburban school-age children. Int J Med Sci. 2010;7:342-353.

39. Ojaimi E, Rose KA, Smith W, Morgan IG, Martin FJ, Mitchell P. Methods for a population-based study of myopia and other eye conditions in school children: the Sydney Myopia Study. Ophthalmic Epidemiol. 2005;12:59-69.

40. O'Donoghue L, Saunders KJ, McClelland JF, et al. Sampling and measurement methods for a study of childhood refractive error in a UK population. Br J Ophthalmol. 2010;94:11501154. 
41. Australian Bureau of Statistics. Australian Standard Classification of Cultural and Ethnic Groups (ASCCEG). Available at: http://abs.gov.au/AUSSTATS/abs@.nsf/DetailsPage/1249. 02005-06? OpenDocument. Accessed June 5, 2012.

42. Rosenberg NA, Pritchard JK, Weber JL, et al. Genetic structure of human populations. Science. 2002;298:2381-2385.

43. Choong YF, Chen AH, Goh PP. A comparison of autorefraction and subjective refraction with and without cycloplegia in primary school children. Am J Ophthalmol. 2006;142:68-74.

44. Ip J, Robaei D, Rochtchina E, et al. Can information on the purpose of spectacle use and age at first use predict refractive error type? Ophthalmic Epidemiol. 2007;14:88-92.

45. Miranda MN. Residual accommodation: a comparison between cyclopentolate $1 \%$ and a combination of cyclopentolate $1 \%$ and tropicamide 1\%. Arch Ophthalmol. 1972;87:515-517.

46. Mayer DL, Hansen RM, Moore BD, Kim S, Fulton AB. Cycloplegic refractions in healthy children aged 1 through 48 months. Arch Ophthalmol. 2001;119:1625-1628.

47. Mutti DO, Mitchell GL, Jones LA, et al. Axial growth and changes in lenticular and corneal power during emmetropization in infants. Invest Ophthalmol Vis Sci. 2005;46:3074-3080.

48. Gordon RA, Donzis PB. Refractive development of the human eye. Arch Ophthalmol. 1985;103:785-789.

49. Sorsby A, Benjamin B, Sheridan M, Stone J, Leary GA. Refraction and its components during the growth of the eye from the age of three. Memo Med Res Counc. 1961;301:1-67.

50. Ojaimi E, Morgan IG, Robaei D, et al. Effect of stature and other anthropometric parameters on eye size and refraction in a population-based study of Australian children. Invest Ophthalmol Vis Sci. 2005;46:4424-4429.

51. Rosner M, Laor A, Belkin M. Myopia and stature: findings in a population of 106,926 males. Eur J Ophthalmol. 1995;5:1-6.

52. Wong TY, Foster PJ, Johnson GJ, Klein BE, Seah SK. The relationship between ocular dimensions and refraction with adult stature: the Tanjong Pagar Survey. Invest Ophthalmol Vis Sci. 2001;42:1237-1242.

53. Wu HM, Gupta A, Newland HS, Selva D, Aung T, Casson RJ. Association between stature, ocular biometry and refraction in an adult population in rural Myanmar: the Meiktila eye study. Clin Exp Ophthalmol. 2007;35:834-839.

54. Saw S-M, Chua W-H, Hong C-Y, et al. Height and its relationship to refraction and biometry parameters in Singapore Chinese children. Invest Ophthalmol Vis Sci. 2002;43: 1408-1413.

55. Teasdale TW, Goldschmidt E. Myopia and its relationship to education, intelligence and height: preliminary results from an on-going study of Danish draftees. Acta Ophthalmol Suppl. 1988; 185:41-43.

56. Johansen EV. Simple myopia in schoolboys in relation to body height and weight. Acta Ophthalmol (Copenh). 1950;28:355361.

57. Goldschmidt E. Myopia and height. Acta Ophthalmologica. 1966;44:751-761.

58. Wang D, Ding X, Liu B, Zhang J, He M. Longitudinal changes of axial length and height are associated and concomitant in children. Invest Ophthalmol Vis Sci. 2011;52:7949-7953.

59. Au Eong KG, Tay TH, Lim MK. Education and myopia in 110,236 young Singaporean males. Singapore Med J. 1993;34: 489-492.

60. Konstantopoulos A, Yadegarfar G, Elgohary M. Near work, education, family history, and myopia in Greek conscripts. Eye (Lond). 2008;22:542-546.

61. Rosner M, Belkin M. Intelligence, education, and myopia in males. Arch Ophthalmol. 1987;105:1508-1511.

62. Saw SM, Cheng A, Fong A, Gazzard G, Tan DT, Morgan I. School grades and myopia. Ophthalmic Physiol Opt. 2007;27: 126-129.
63. Saw S-M, Wu H-M, Seet B, et al. Academic achievement, close up work parameters, and myopia in Singapore military conscripts. Br J Ophthalmol. 2001;85:855-860.

64. Tay MT, Au Eong KG, Ng CY, Lim MK. Myopia and educational attainment in 421,116 young Singaporean males. Ann Acad Med Singapore. 1992;21:785-791.

65. Wong L, Coggon D, Cruddas M, Hwang CH. Education, reading, and familial tendency as risk factors for myopia in Hong Kong fishermen. J Epidemiol Community Health. 1993; 47:50-53.

66. Wu HM, Seet B, Yap EPH, Saw SM, Lim TH, Chia KS. Does education explain ethnic differences in myopia prevalence: a population-based study of young adult males in Singapore. Optom Vis Sci. 2001;78:234-239.

67. Zylbermann R, Landau D, Berson D. The influence of study habits on myopia in Jewish teenagers. J Pediatr Ophthalmol Strabismus. 1993;30:319-322.

68. Thomson S, De Bortoli L, Nicholas M, Hillman K, Buckley S. Challenges for Australian Education: Results from PISA 200. The PISA 2009 Assessment of Students' Reading, Mathematical and Scientific Literacy. Camberwell, Victoria: ACER Press, The Australian Council for Educational Research Ltd; 2011. Available at: http://www.acer.edu.au/ozpisa/reports/. Accessed June 5, 2012.

69. Bradshaw J, Sturman L, Vappula H, Ager R, Wheater R. Achievement of 15-Year-Olds in England: PISA 2006 National Report. OECD Programme for International Student Assessment. Slough, United Kingdom: National Foundation for Educational Research (NFER); 2007. Available at: www. nfer.ac.uk/nfer/publications/NPC02/NPC02.pdf. Accessed June 5, 2012.

70. Rose KA, Morgan IG, Ip J, et al. Outdoor activity reduces the prevalence of myopia in children. Ophthalmology. 2008;115: 1279-1285.

71. Wu P-C, Tsai C-L, Hu C-H, Yang Y-H. Effects of outdoor activities on myopia among rural school children in Taiwan. Ophthalmic Epidemiol. 2010;17:338-342.

72. Jones-Jordan LA, Mitchell GL, Cotter SA, et al. Visual activity before and after the onset of juvenile myopia. Invest Ophthalmol Vis Sci. 2011;52:1841-1850.

73. Deng L, Gwiazda J, Thorn F. Children's refractions and visual activities in the school year and summer. Optom Vis Sci. 2010; 87:406-413.

74. Ashby R, Ohlendorf A, Schaeffel F. The effect of ambient illuminance on the development of deprivation myopia in chicks. Invest Ophthalmol Vis Sci. 2009;50:5348-5354.

75. Ashby RS, Schaeffel F. The effect of bright light on lens compensation in chicks. Invest Ophthalmol Vis Sci. 2010;51: 5247-5253.

76. The Irish Meteorological Association (MET.IE). Sunshine and solar radiation. Available at: http://www.met.ie/ climate-ireland/sunshine.asp. Accessed June 5, 2012.

77. Australian Government: Bureau of Meterology. Average annual and monthly sunshine duration. Available at: http://www. bom.gov.au/jsp/ncc/climate_averages/sunshine-hours/index. jsp?period=an. Accessed June 5, 2012.

78. Atmospheric Data and Science Centre and NASA. Surface meteorology and solar energy. Available at: http://eosweb.larc. nasa.gov/cgi-bin/sse/sse.cgi?+s01. Accessed June 5, 2012.

79. Cordain L, Eaton SB, Brand Miller J, Lindeberg S, Jensen C. An evolutionary analysis of the aetiology and pathogenesis of juvenile-onset myopia. Acta Ophthalmol Scand. 2002;80:125135.

80. Lim LS, Gazzard G, Low Y-L, et al. Dietary factors, myopia, and axial dimensions in children. Ophthalmology. 2010;117:993997.e4.

81. Sharma A, Congdon N, Gao Y, et al. Height, stunting, and refractive error among rural Chinese schoolchildren: the See 
Well to Learn Well Project. Am J Ophthalmol. 2010;149:347353.e1.

82. Ip JM, Rose K, Morgan I, Burlutsky G, Mitchell P. Myopia and the urban environment: findings for a sample of 12-year old Australian school children. Invest Ophthalmo Vis Sci. 2008;49: 3858-3863.

83. Zhang M, Li L, Chen L, et al. Population density and refractive error among Chinese children. Invest Ophthalmol Vis Sci. 2010;51:4969-4976.

84. Northern Ireland Statistics and Research Agency (NISRA). Population statistics. 1981-2010. Available at: http://www. nisra.gov.uk/demography/default.asp3.htm. Accessed June 5, 2012.

85. Smith G. Sydney, a social atlas: 2006 census of population and housing. Australian Bureau of Statistics Web site. Available at: http://www.abs.gov.au/AUSSTATS/abs@.nsf/DetailsPage/2030. 12006? OpenDocument. Updated 2008. Accessed June 5, 2012.
86. Huynh SC, Kifley A, Rose KA, Morgan I, Heller GZ, Mitchell P. Astigmatism and its components in 6-year-old children. Invest Ophthalmol Vis Sci. 2006;47:55-64.

87. Huynh SC, Kifley A, Rose KA, Morgan IG, Mitchell P. Astigmatism in 12-year-old Australian children: comparisons with a 6-year-old population. Invest Ophthalmol Vis Sci. 2007; 48:73-82.

88. O'Donoghue L, Rudnicka AR, McClelland JF, Logan NS, Owen CG, Saunders KJ. Refractive and corneal astigmatism in white school children in Northern Ireland. Invest Ophthalmol Vis Sci. 2011;52:4048-4053.

89. Kleinstein RN, Jones LA, Hullett $S$, et al. Refractive error and ethnicity in children. Arch Ophthalmol. 2003;121:1141-1147.

90. Czepita D, Mojsa A, Ustianowska M, Czepita M, Lachowicz E. Prevalence of refractive errors in schoolchildren ranging from 6 to 18 years of age. Ann Acad Med Stetin. 2007;53:53-56. 